RBC-rich (5\% plasma:95\% RBCs). The blood mixture was injected in $6 \mathrm{~F}$ guide angiographic catheter though a syringe. OPTISTM Integrated System (St. Jude Medical Inc., St. Paul, Minnesota) was used to perform OCT testing for each clot. A Dragonfly $^{\mathrm{TM}}$ OPTIS $^{\mathrm{TM}}$ imaging catheter (St. Jude Medical $\mathrm{GmbH}$, St. Paul, Minnesota) was advanced into the catheter to pass the clot. The rate of automatic pullback was $0.5 \mathrm{~mm} /$ s. The blood clot was identified by OCT on mass images with different signal characters. OCT images were processed and analyzed according to the intensity of OCT signals from different compositions of clot.

Results Homogeneous signal of clot was shown in all the clots in Group A and B, less signal attenuation from its surface to inside was noted, which indicated high penetration (low-back scattering). Intermediate signal attenuation from its surface to inside was shown in all the clots in Group $\mathrm{C}$, in which some signals still existed at the periphery of the clot. Clot in Group $\mathrm{D}$ and $\mathrm{E}$ was superficial signal rich with more signal attenuation from its surface to inside, which indicated low penetration (high-back scattering). Three clots in Group E showed signal-free shadowing (figures A to E).

Conclusion Different composition of clots can be assessed by OCT. Fibrin-rich clots have homogeneous signal with high penetration (low-back scattering), while RBC-rich clot can be recognized as superficial signal rich with low penetration (high-back scattering).

Disclosures Y. Ding: None. M. Abbassi: None. D. Jakaitis: None. D. Dai: None. R. Kadirvel: None. D. Kallmes: None. W. Brinjikji: None.

\section{E-177 CARDIOVASCULAR RISK FACTORS ARE ASSOCIATED WITH CAROTID ARTERY INTRAPLAQUE HEMORRHAGE}

${ }^{1} \mathrm{~A}$ Larson*, ${ }^{2} \mathrm{~J}$ Benson, 'G Lanzino, ${ }^{2} \mathrm{~W}$ Brinjikji. 'Neurosurgery, Mayo Clinic, Rochester, $M N_{i}^{2}$ Radiology, Mayo Clinic, Rochester, MN

\subsection{6/neurintsurg-2020-SNIS.209}

Background Intraplaque hemorrhage (IPH) has been shown to be a predictor of symptomatic carotid artery disease, independent of degree of carotid stenosis. The association between modifiable cardiovascular risk factors, demographics and lab values has not been extensively studied.

Methods We reviewed our institutional series of patients who have undergone dedicated carotid plaque imaging over a 3year period and report the association between various demographic and clinical variables and the presence of plaque hemorrhage. Patients with dedicated carotid plaque imaging were categorized into two groups: those with IPH and those without.

Results 643 total patients were reviewed. 114 patients $(17.7 \%)$ had intraplaque hemorrhage on carotid plaque imaging sequences compared to 529 patients $(82.3 \%)$ without. Patients with IPH had a mean age of 76.0 years compared to 60.1 years in those without IPH $(\mathrm{P} \leq 0.0001)$. $79 \%$ of patients with IPH were male, compared to $49.5 \%$ without IPH ( $\mathrm{P} \leq 0.0001)$. $39.5 \%$ of patients with IPH had coronary artery disease compared to $23.1 \%$ of patients without IPH $(\mathrm{P}=0.0003)$. The IPH group also had higher proportions of patients with hypertension $(77.2 \%$ vs. $60.7 \%, \mathrm{P}=0.009)$, hyperlipidemia $(89.5 \%$ vs. $62.4 \%, \mathrm{P} \leq 0.0001)$, diabetes mellitus $(89.5 \%$ vs. $62.4 \%$, $\mathrm{P}=0.01)$ and a history of tobacco smoking $(63.2 \%$ vs. $52.6 \%$, $\mathrm{P}=0.003)$ as compared those without IPH.
Abstract E-177 Table 1

\begin{tabular}{llll}
\hline & IPH & Without IPH & P \\
\hline N Total & $114(17.7)$ & $529(82.3)$ & - \\
Any Carotid Stenosis $>30 \%$ & $93(81.6)$ & $154(29.1)$ & $<0.0001$ \\
Mean Age (SD) & $76(8.0)$ & $60.1(17.4)$ & $<0.0001$ \\
N (\%) Male & $90(79.0)$ & $262(49.5)$ & $<0.0001$ \\
Comorbidities & & & \\
CAD & $45(39.5)$ & $122(23.1)$ & 0.0003 \\
HTN & $88(77.2)$ & $321(60.7)$ & 0.0009 \\
HLP & $102(89.5)$ & $330(62.4)$ & $<0.0001$ \\
DM & $33(29.0)$ & $99(18.7)$ & 0.01 \\
PAD & $6(5.3)$ & $41(7.8)$ & 0.35 \\
OSA & $28(24.5)$ & $114(21.6)$ & 0.53 \\
A-fib & $18(15.8)$ & $64(12.1)$ & 0.28 \\
Current or Former Smoker & $72(63.2)$ & $278(52.6)$ & 0.003 \\
Lab Values & & & \\
BMI & $28.7(5.0)$ & $28.3(5.6)$ & 0.52 \\
LDL & $86.6(33.4)$ & $91.9(36.0)$ & 0.15 \\
HDL & $46.1(13.7)$ & $50.7(16.1)$ & 0.003 \\
TG & $145.8(129.8)$ & $150.5(288.8)$ & 0.81 \\
BG & $123.4(51.4)$ & $113.8(39.1)$ & 0.07 \\
CRP & $24.2(49.7)$ & $19.2(43.4)$ & 0.56 \\
\hline Abrevis) & & & \\
\hline
\end{tabular}

Abbreviations: $\mathrm{BMI}=$ body mass index, $\mathrm{CAD}=$ coronary artery disease, $\mathrm{HTN}=$ hyperten sion, $\mathrm{HLD}=$ hyperlipidemia, $\mathrm{DM}=$ diabetes mellitus, IPH = intraplaque hemorrhage, PAD = peripheral artery disease, OSA = obstructive sleep apnea, A-fib = atrial fibrillation, $L D L$ = low density lipoprotein, $\mathrm{HDL}=$ high density lipoprotein, $\mathrm{TG}=$ triglycerides, $\mathrm{BG}=$ blood glucose, $C R P=c$-reactive protein

Conclusions IPH is associated with well-known non-modifiable and modifiable cardiovascular risk factors. Patients with these risk factors are therefore more likely to have IPH within carotid plaques as compared to patients without these risk factors. These factors likely play a role in IPH pathophysiology. Consideration of such risk factors is important in considering patients to be at risk for ischemic stroke from carotid plaque. Disclosures A. Larson: None. J. Benson: None. G. Lanzino: None. W. Brinjikji: None.

\section{E-178 A RADIAL FIRST APPROACH FOR DIAGNOSTIC CEREBRAL ANGIOGRAPHY: COMPARISON OF PROCEDURE AND SAFETY PARAMETERS FOR TRANSRADIAL AND TRANSFEMORAL ACCESS}

${ }^{1} \mathrm{~T}$ Peebles*, ${ }^{1} \mathrm{D}$ Conners, ${ }^{2} \mathrm{~A}$ Peebles, ${ }^{3} \mathrm{~J}$ Garland. 'Radiology Associates of the Fox Valley, Neenah, WI; ${ }^{2}$ Carleton College, Northfield, MN; ${ }^{3}$ Ascension Health Care, Milwaukee, WI

\subsection{6/neurintsurg-2020-SNIS.210}

Background and Purpose Transradial diagnostic cerebral angiography is slowly gaining acceptance due to significant safety advantages over transfemoral angiography, but there is limited data comparing other procedure parameters between the two techniques. We document the impact of adopting a 'radial first' diagnostic cerebral angiography in a busy multihospital setting.

Methods Six hundred forty-five consecutive patients referred for diagnostic 4-vessel cerebral angiography were considered for primary radial access over a three-year period. Radial access procedure data were analyzed retrospectively using prospectively maintained data. Radial procedure parameters were 
Abstract E-178 Table 1 Comparison of Femoral to Radial Access Procedure Metrics (values are mean, median (IQR))

\begin{tabular}{|c|c|c|c|c|c|}
\hline Metric & Femoral $(n=250)$ & Entire Radial Cohort $(n=545)$ & Reduced Radial Cohort $(n=445)$ & $\begin{array}{l}\text { Significance (femoral vs } \\
\text { entire radial cohort) }\end{array}$ & $\begin{array}{l}\text { Significance (femoral vs } \\
\text { reduced radial cohort) }\end{array}$ \\
\hline Vessels injected & $3.9,4(3)$ & $3.9,4(3)$ & $4,3(3)$ & $\mathrm{p}=0.69$ & $\mathrm{p}=0.42$ \\
\hline Duration (min) & $22,21(10)$ & $25,24(13)$ & $24,23(14)$ & $p<0.001$ & $p<0.001$ \\
\hline Duration/vessel (min) & $7.7,5.5(5.9)$ & $8.5,6.5(5.4)$ & $7.5,6(4.6)$ & $\mathrm{p}<0.001$ & $p=0.30$ \\
\hline Fluoro time (min) & $5.2,4.6(3.8)$ & $7.6,6.7(5.5)$ & $7.4,6.6(5.4)$ & $p<0.001$ & $p<0.001$ \\
\hline Fluoro time/vessel (min) & $1.7,1.3(1.0)$ & $2.4,1.8(1.4)$ & $2.0,1.6(1.1)$ & $p<0.001$ & $p<0.001$ \\
\hline Fluoro dose (mGy) & $318,220(229)$ & 290, $237(219)$ & $293,240(225)$ & $p=0.90$ & $\mathrm{p}=0.74$ \\
\hline Fluoro dose/vessel (mGy) & $94,70(72)$ & $89,67(55)$ & $83,65(52)$ & $\mathrm{p}=0.35$ & $p=0.06$ \\
\hline Contrast dose $(\mathrm{mL})$ & $63,60(45)$ & $60,60(40)$ & $60,60(40)$ & $p=0.33$ & $\mathrm{p}=0.37$ \\
\hline Contrast/vessel (mL) & $19.7,16(10.6)$ & $18.5,15(9.6)$ & $17,15(8.8)$ & $\mathrm{p}=0.05$ & $\mathrm{p}<0.001$ \\
\hline
\end{tabular}
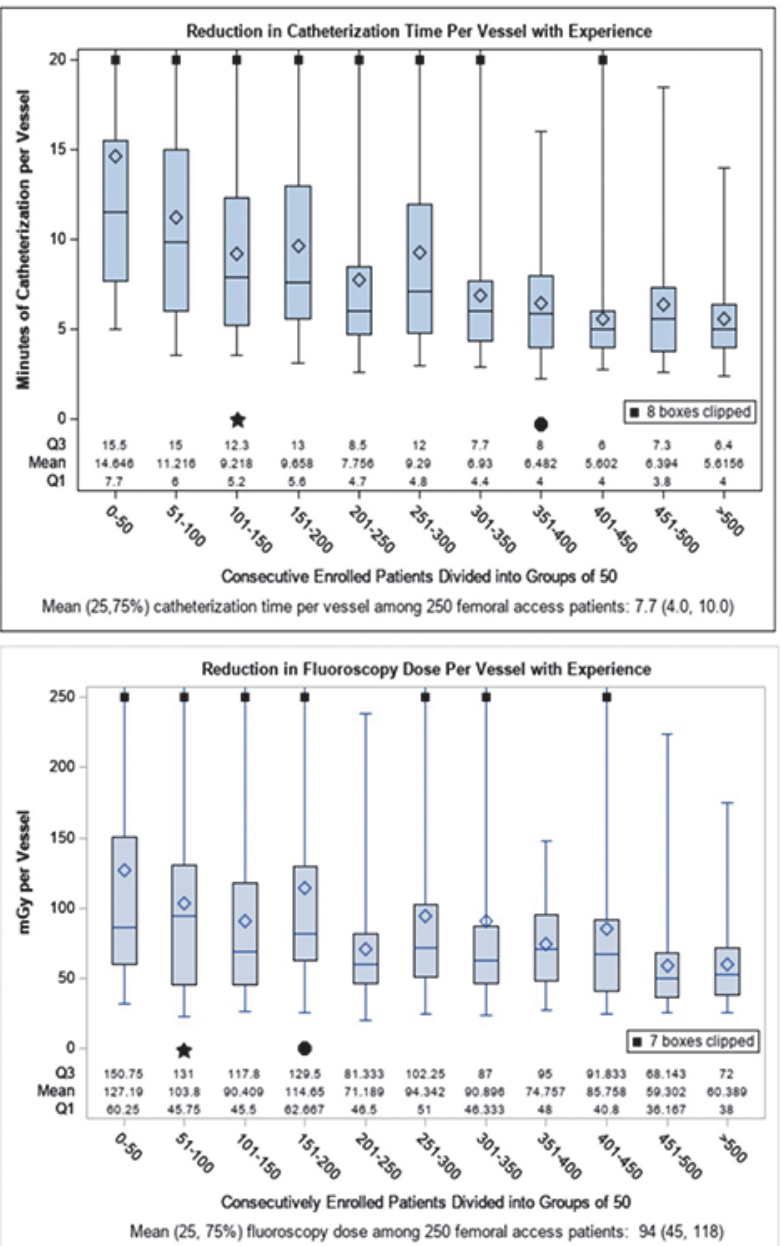

\section{Abstract E-178 Figure 1}

compared to a cohort of two hundred fifty consecutive transfemoral cerebral angiograms from the preceding year.

Results Five hundred forty-five patients of 645 patients (84\%) underwent primary radial access for diagnostic cerebral angiography (460 proximal radial, 85 distal radial). Compared to the femoral standard, radial cohort procedure duration/vessel and fluoroscopy time/vessel were significantly longer, but the fluoroscopy dose/vessel was statistically similar. The radial contrast dose/vessel was significantly less than the femoral standard. With experience, radial procedure duration/vessel and fluoroscopy dose/vessel became significantly better than the femoral standard and the fluoroscopy time/vessel become statistically similar at the $\mathrm{p}=0.05$ level. The radial to femoral conversion rate was $3.3 \%$. There were no major periprocedural complications in the radial group.

Conclusions With experience, transradial cerebral angiography became better than or equal to the femoral standard in all procedure parameters with fewer complications and equal diagnostic utility. These findings add additional support for expanding use of transradial access for routine cerebral angiography.

Disclosures T. Peebles: 2; C; Terumo Medical. 4; C; RIST Neurovascular. D. Conners: None. A. Peebles: None. J. Garland: None.

\section{E-179 TACTILE DEFORMABLE SOFT ROBOTS FOR ENDOVASCULAR MICROCATHETER NAVIGATION, PLACEMENT AND STABILITY}

${ }^{1} \mathrm{~T}$ Gopesh*, ${ }^{2} \mathrm{~J}$ Wen, ${ }^{3} \mathrm{D}$ Santiago-Dieppa, ${ }^{4} \mathrm{~B}$ Yan, ${ }^{3} \mathrm{~J}$ Scott-Pannell, ${ }^{1} \mathrm{~A}$ Khalessi, ${ }^{5} \mathrm{~A}$ Norbash, ${ }^{1} \mathrm{~J}$ Friend. ${ }^{1}$ Mechanical and Aerospace Engineering, University of California San Diego, San Diego, $C A_{;}{ }^{2}$ School of Medicine, University of California San Diego, San Diego, $C A ;{ }^{3}$ Neurosurgery, University of California San Diego, San Diego, $C A ;{ }^{4}$ Neurosciences, Melbourne Brain Centre, Melbourne, AUSTRALIA; ${ }^{5}$ Radiology, University of California San Diego, San Diego, CA

\subsection{6/neurintsurg-2020-SNIS.211}

Endovascular procedures are limited by an absence of effective actuation methods for navigation and precise device positioning. The existing panoply of passive guidewires and catheters for the treatment of cerebral aneurysms, in particular, leaves neurointerventionists without a treatment option in at least $25 \%$ of patients. A key reason is the inability to steer the tip of the microcatheters in vivo. We overcome this problem with sub-millimeter diameter hydraulically-actuated hyperelastic polymer devices connected over a $160 \mathrm{~cm}$ length. These provide controlled 3D orientation of acute tip curvatures beyond 180 degrees at pressures of $400 \mathrm{kPa}$ that achieves stable coil deployment in vivo. This method uses saline as the working fluid, and forms a closed system from the steerable tip to the hydraulic actuator offering safety, ease of use, and design flexibility absent in approaches that require external actuation.

Disclosures T. Gopesh: None. J. Wen: None. D. Santiago-Dieppa: None. B. Yan: None. J. Scott-Pannell: None. A. Khalessi: None. A. Norbash: None. J. Friend: None. 